\title{
Clinical costs escalate biotechnology's R\&D expenses
}

The continued growth in biotechnology R\&D spending (see "Public companies spend over $\$ 4$ billion on R\&D," p. 934) is largely attributable to the deepening product pipelines of biotechnology firms and the advancing developmental stage of many of these products.

A sudden spurt in $\mathrm{R} \& \mathrm{D}$ outlays typically accompanies the progression of a product into clinical trials or advancement to the next stage of trials, as a company incurs huge costs for developing and running the trials, scaling up manufacturing processes, and analyzing the data.

"You should be able to tie significant cost increases to progress in the clinic," states Steven S. Cowell, vice president of finance and chief financial officer of Agouron. "You could look back at Agouron's 1993, 1994, and 1995. . .R\&D line, and. . .almost track when we transitioned from a research agenda to a preclinical development agenda, into a phase I or phase II agenda." In 1995, Agouron did increase its R\&D spending, $51.6 \%$ to $\$ 36.32$ million. The company's HIV protease inhibitor, Viracept, was in multiple phase III trials in more than 700 patients, and the chemotherapeutic agent Thymitaq began phase III testing.

Once a product gets FDA approval, the program cost will decline. "It doesn't go to zero, but it may decrease from the peak activity required to get the product approved initially," notes Cowell. More products in the pipeline follow, however, and continue to increase costs. "You may never see a spike in your spending followed by a decline because you have product approval; you may simply get a new plateau or a new level of stability," Cowell adds. Companies cannot realistically maintain large increases in $\mathrm{R} \& \mathrm{D}$ spending, however, and must determine the number of concurrent clinical programs they can support without compromising their fundamental research programs. Even though investors have come back io biotechnology over the past year, many companies now need revenues from product sales to fund their growing clinical agenda.

Large increases in $R \& D$ expenditure are not only linked to demand-the clinical pipeline-but also, necessarily, to the supply of money. Genome Therapeutics (GT, Waltham, MA), for instance, struck deals worth more than $\$ 11$ million in license fees and research funding with Astra $\mathrm{AB}$ (Sweden), \$6-10 million in first-year payments alone from Schering Plough (Madison, NJ) in 1995, and a public offering in February 1996 added $\$ 40$ million more to their bill. "In the last year, through the collaborations we have consummated with pharmaceutical companies, we have been able to bring some capital into the company," says Fenel Eloi, GT's chief financial officer. As a result, GT increased both collaborator-sponsored research and company-funded $\mathrm{R} \& \mathrm{D}$ programs last year. Its $\mathrm{R} \& \mathrm{D}$ spending increase $350.7 \%$ from around $\$ 350,000$ in 1994 to $\$ 1.24$ million in 1995 . Eloi predicts $420 \%$ growth in 1996 to about $\$ 6.5$ million, and a further $50 \%$ or more increase to about $\$ 9$ million in 1997.

For some other companies, a large jump in $\mathrm{R} \& \mathrm{D}$ spending in 1995 reflects a one-time acquisition of technology. Nearly $\$ 10 \mathrm{mil}-$ lion of Boston Life Sciences' (Waltham, MA) $\$ 11.87$ million R\&D figure for 1995 (241.1\% up on 1994) is attributable to its merger with Greenwich Pharmaceuticals (Fort Washington, PA). Similarly, virtually all of the $119 \%$ increase in R\&D spending (from $\$ 8.4$ million to $\$ 16.7$ million in 1995) reported by Aronex Pharmaceuticals (The Woodlands, TX) is attributable to the cost of purchasing R\&D during the three-way merger of Argus Pharmaceutical, Triplex Pharmaceutical (both The Woodlands, TX), and Oncologix (Gaithersburg, MD) that formed Aronex in September 1995.

Jumps downward in R\&D spending can occur, too, and for similar reasons. Centocor's reported $37.2 \%$ drop is a consequence of its 1994 figure of $\$ 105.4$ million being inflated by $\$ 36$ million-the cost of buying back the rights to technology owned by an R\&D partnership. Even accounting for this, Centocor's R\&D costs did drop nearly $\$ 4$ million due mainly to fewer clinical trials. The company is initiating several clinical trials this year, including five designed to expand the labeling of ReoPro, its monoclonal antibody product used in angioplasty. Expect higher R\&D figures for 1996.

But just how much do clinical trials cost? Neurobiological Technologies (NTI, Richmond, CA), which licenses drug candidates and takes them into the clinic, can attribute nearly all of its $68.3 \%$ increase in $R \& D$ spending, up to $\$ 4.45$ million, to rising clinical research costs. The company advanced its lead products from preclinical into phase II testing. At an estimated cost of $\$ 2500-\$ 5000$ per patient paid to each testing site, and more if a contract research organization manages the trial, costs mount quickly in phase II and III studies. NTI ran trials involving three times as many patients in 1995 as it did in 1994. Drugs to treat chronic diseases, such as NTI's corticotropin-releasing factor for rheumatoid arthritis and asthma, and Dynorphin A for chronic pain require extensive toxicity studies, at a cost of as much as $\$ 250,000$ per month.
Amgen (Thousand Oaks, CA) still leads the list of R\&D spending: Its spending was up $39.6 \%$ in 1995 to $\$ 451.7$ million, which resulted from both an expanding product pipeline and the company having more drugs in later stage, larger, clinical trials. In 1994, Amgen had six products (Epogen, Neupogen and four "others") in clinical development. In 1995, there were six "other" products, and in 1996, Amgen will have 13 drugs plus Epogen and Neupogen in clinical trials. The company's R\&D figures should take a huge leap for 1996. Another factor in

\section{Just how much do clinical trials cost? Neurobiological Technologies, which licenses drug candidates and takes them into the clinic, can attribute nearly all of its $68.3 \%$ increase in R\&D spend- ing, up to $\$ 4.45$ million, to rising clinical research costs.}

Amgen's growing $\mathrm{R} \& \mathrm{D}$ expenses is salaries: The company has grown from about 260 medical doctors and PhDs in 1994, to nearly 400 in 1996.

Nearly $\$ 96.4$ million of Chiron's notable $106.9 \%$ rise in $R \& D$ spending in 1995 to $\$ 343.75$ million is due to acquisitions in 1995 . The remaining $\$ 88$ million or so largely represents increased clinical trial activity.

With over $\$ 8$ billion of new funding raised by biotechnology companies in general from investors in the 12 months since July 1995, it is highly likely that R\&D spending will increase dramatically in 1996. The clinical effort has already stepped up considerably. According to the Biotechnology Industry Organization (Washington, DC), a forum for US companies, 234 biotechnology drugs were in various stages of clinical testing during 1995. Half-way through 1996, that figure was already 284, with 127 compounds in phase III, 205 in phase II, and 144 in phase I (a compound may be in more than one phase of testing).

Vicki Glaser 